NASA/CR-1998-206609

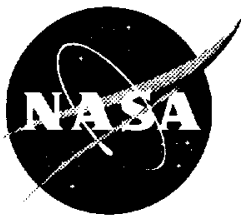

\title{
Heat Transfer on a Film-Cooled Blade - Effect of Hole Physics
}

Vijay K. Garg

AYT Corporation, Cleveland, Ohio

David L. Rigby

NYMA, Inc., Brook Park, Ohio

Prepared for the

Turbo Expo 1998

sponsored by the American Society of Mechanical Engineers

Stockholm, Sweden, June 2-5, 1998

Prepared under Contract NAS3-27571

National Aeronautics and

Space Administration

Lewis Research Center 
This report is a formal draft or working paper, intended to solicit comments and ideas from a technical peer group.

This report contains preliminary findings, subject to revision as analysis proceeds.

This report is a preprint of a paper intended for presentation at a conference. Because of changes that may be made before formal publication, this preprint is made available with the understanding that it will not be cited or reproduced without the permission of the author.

Available from

NASA Center for Aerospace Information 800 Elkridge Landing Road

Linthicum Heights, MD 21090-2934

Price Code: A03
National Technical Information Service 5287 Port Royal Road Springfield, VA 22100

Price Code: $\mathrm{A} 03$ 


\title{
HEAT TRANSFER ON A FILM-COOLED BLADE - EFFECT OF HOLE PHYSICS
}

\author{
Vijay K. Garg \\ AYT Corporation \\ NASA Lewis Research Center \\ Mail Stop 5-11, Cleveland, OH 44135 \\ David L. Rigby \\ NYMA, Inc. \\ NASA Lewis Research Group \\ Brook Park, OH 44142
}

\begin{abstract}
A multi-block, three-dimensional Navier-Stokes code has been used to study the within-hole and near-hole physics in relation to heat transfer on a film-cooled blade. The flow domain consists of the coolant flow through the plenum and hole-pipes for the three staggered rows of shower-head holes on the VKI rotor, and the main flow over the blade. A multi-block grid is generated that is nearly orthogonal to the various surfaces. It may be noted that for the VKI rotor the shower-head holes are inclined at $30^{\circ}$ to the spanwise direction, and are normal to the streamwise direction on the blade. Wilcox's $k$ - $\omega$ turbulence model is used. The present study provides a much better comparison for the span-averaged heat transfer coefficient on the blade surface with the experimental data than an earlier analysis wherein coolant velocity and temperature distributions were specified at the hole exits rather than extending the computational domain into the hole-pipe and plenum. Details of the distributions of coolant velocity, temperature, $k$ and $\omega$ at the hole exits are also presented.
\end{abstract}

\section{NOMENCLATURE}

c true chord of the blade

D coolant hole diameter

DR ratio of coolant density to mainstream flow density

$h$ heat transfer coefficient based on $\left(\mathrm{T}_{\mathrm{o}}-\mathrm{T}_{w}\right)$

k turbulence kinetic energy

$\ell$ turbulence length scale

$\mathrm{L}$ length of the hole-pipe

m mass flow rate

M Mach number; also leading-edge mid-row hole-pipe at $s / c=0$

p pressure

$P \quad$ leading-edge hole-pipe on the pressure side at $s / c=-0.031$

Pr Prandtl number

q square root of turbulence kinetic energy

$R \quad$ gas constant

Re Reynolds number

$s$ distance from the leading edge along the pressure or suction surface

$S \quad$ leading-edge hole-pipe on the suction side at $\mathrm{s} / \mathrm{c}=0.031$; also stagnation point

T temperature

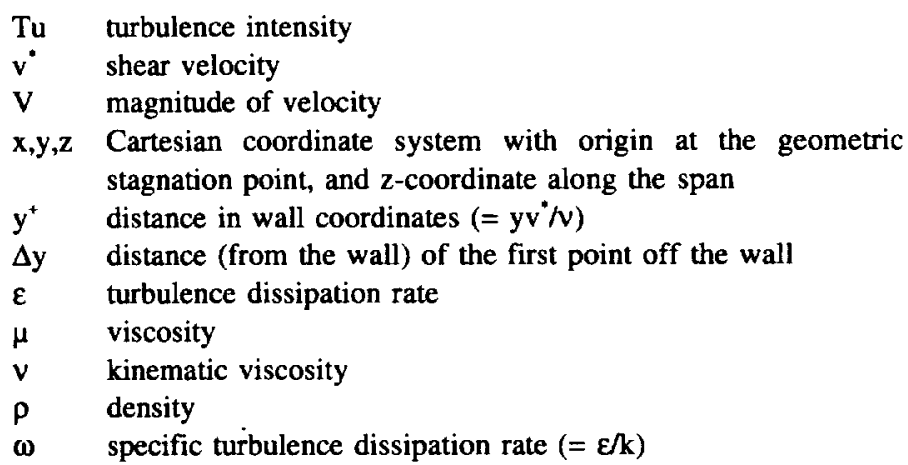

\section{Subscripts}

\begin{tabular}{ll}
\hline av & average value \\
c & for coolant; also corresponding to true chord of the blade \\
ef & effective value \\
ex & value at exit \\
in & value at inlet \\
l & laminar value \\
m & for main flow \\
o & stagnation value \\
s & isentropic value \\
T & turbulent value \\
w & value at wall
\end{tabular}

\section{INTRODUCTION}

It is well known from the thermodynamic analysis that the performance of a gas turbine engine is strongly influenced by the temperature at the inlet to the turbine. There is thus a growing tendency to use higher turbine inlet temperatures, implying increasing heat loads to the engine components. Modern gas turbine engines are designed to operate at inlet temperatures of $1800-2000 \mathrm{~K}$, which are far beyond the allowable metal temperatures. Thus, to maintain acceptable life and safety standards, the structural elements need to be protected against the severe thermal environment. This calls for an efficient cooling system. One such cooling technique currently used for high temperature turbines is film cooling. In this technique, cooler air is injected into the high temperature boundary layer on the blade surface. 
Since the injected cooler air is bled directly from the compressor before it passes through the combustion chamber, it represents a loss in the total power output. The designer's goal is therefore to minimize the amount of coolant necessary to insure adequate engine life. Unfortunately, the thermal design of a film-cooled blade is still based on one-dimensional analysis and empirical correlations, thereby requiring actual testing of every design concept. In such a situation, only minor variations of existing designs are adopted since any novel ideas are too expensive to test thoroughly. There is thus an urgent need to be able to predict accurately the heat transfer characteristics of film-cooled blades before actually testing them in the engine.

A considerable effort has been devoted to understanding the coolant film behavior and its interaction with the mainstream flow. The film cooling performance is influenced by the wall curvature, three-dimensional external flow structure, free-stream turbulence, compressibility, flow unsteadiness, the hole size, shape and location, and the angle of injection. Interest in this field has grown considerably in recent years. However, many studies on film cooling have been confined to simple geometries, for example, two-dimensional flat and curved plates in steady, incompressible flow.

An excellent survey of the film-cooling work up to 1971 has been provided by Goldstein (1971). Several further studies in this field have been summarized by Garg and Gaugler (1993, 1994, 1996). A number of parametric studies have been performed by Garg and co-workers to determine the effect of several parameters, such as the effect of coolant velocity and temperature distributions at the hole exit (Garg and Gaugler, 1997b), the effect of blade rotation and of the direction of coolant injection from the shower-head holes (Garg, 1997a), the effect of spanwise pitch of shower-head holes (Garg and Gaugler, 1996), the effect of coolant to mainstream mass flow and temperature ratio (Garg and Gaugler, 1997a), and the effect of turbulence modeling (Garg and Abhari, 1997; Garg and Ameri, 1997; Garg, 1997b, 1997c). Four turbulence models, the Baldwin-Lomax model, Coakley's $q-\omega$ model, Chien's $\mathrm{k}-\varepsilon$ model, and Wilcox's $k$ - $\omega$ models have been analyzed, and results compared with the experimental data for heat transfer from rotating as well as stationary blades. In all these studies by Garg and co-workers, coolant velocity and temperature distributions were prescribed at the hole exits; there was no attempt to analyze the coolant within the plenum and hole-pipes.

Of all the effects described above, the effect of coolant velocity and temperature distributions at the hole exit has the largest influence on the heat transfer from the blade surface, as much as $60 \%$ at the blade suction surface, and $50 \%$ at the pressure surface. Clearly, there is a need for better understanding of the coolant conditions at the hole exit. There are no experimental data for these distributions at the exit of a hole on a real blade. Also, no computational studies have been performed to describe these distributions in the case of a real blade, specially with compound-angle injection, representative of the showerhead holes. Some recent studies have focussed on the hole-exit conditions, but on a flat plate or a circular cylinder.

Pietrzyk et al. (1989) provided Laser Doppler anemometry data for the coolant velocity profiles at a $35^{\circ}$ streamwise-angled hole exit on a flat plate for density ratio (DR) of unity and two. Besides the three mean velocity components, they also measured six turbulence stresses from one diameter upstream of the holes to 30 diameters downstream. However, no temperature distributions were measured. This basic geometry has been investigated extensively for both experimental as well as numerical studies. Burd et al. (1996), and Burd and Simon (1997) reported hot-wire and thermocouple measurements at the hole exit on a flat plate for $35^{\circ}$ streamwise-angled holes with the hole-length to diameter ratio (L/D) of 2.3 and 7.0 , and DR of unity. Freestream turbulence levels of $0.5 \%$ and $12 \%$ were investigated. Also, geometry of the plenum supplying the coolant to the holes was varied. However, none of the plenum geometries simulated the condition that exists on a real turbine blade.

Leylek and Zerkle (1994) analyzed the streamwise-angled hole at $35^{\circ}$ on a flat plate using the standard $k-\varepsilon$ turbulence model with wall functions for $\mathrm{DR}=2$, and $\mathrm{L} / \mathrm{D}$ of 1.75 and 3.5. Following the coolant from the plenum into the hole-pipe, they presented coolant velocity and temperature profiles at the hole exit. However, the coolant was fed directly into the hole-pipe from a large plenum, unlike that in a real blade. More recently, Berhe and Patankar $(1996,1997)$ have analyzed the same geometry as that of Leylek and Zerkle, and presented similar results. Giebert et al. (1997) analyzed the flow field at the exit of a cylindrical and two shaped holes on a flat plate using the standard $k-\varepsilon$ model with wall functions. They compared the numerical results with detailed flow field measurements of mean velocity and turbulence quantities for a DR of unity. Discrepancies were found when comparing the flow field inside the hole and at the hole exit. In particular, jet location at the hole exit differed significantly from measurements for the shaped holes.

In a series of papers, Leylek and his co-workers have analyzed streamwise and compound-angled holes, both cylindrical and shaped, on a flat plate using the Fluent unstructured code. The coolant is traced from the plenum into the hole-pipe and its interaction with the mainstream is analyzed. Walters and Leylek (1997) investigated the same geometry as was analyzed by Leylek and Zerkle (1994) with an emphasis on vorticity based approach, while McGovern and Leylek (1997) analyzed its counterpart for compound-angle injection. Hyams and Leylek (1997) investigated the streamwise-angled shaped hole on a flat plate for $\mathrm{DR}=1.6$ and $\mathrm{LD}=4$ using the $k-\varepsilon$ model with wall functions, while Brittingham and Leylek (1997) analyzed its compound-angle counterpart. In all these studies, the coolant was fed directly into the hole-pipe from the plenum, and only one row of holes (only one hole for analysis) was investigated. Thus, no interaction between adjacent coolant rows was possible.

While the hole-exit conditions seem to have been studied well on a flat plate, there is no such experimental or numerical investigation on a real blade. Bohn et al. (1997) did analyze two staggered rows of shower-head holes on a turbine guide vane, tracing the coolant from the plenum into the hole-pipe and beyond the exit on the vane. However, their interest was not in the hole-exit profiles. Also, the hole axis was taken to be normal to the vane surface, unlike the compoundangled shower-head holes on a real blade. Assuming symmetry conditions on the upper and lower surfaces in the spanwise direction, their computational domain contained two half hole-pipes and a thin slice of the coolant plenum chamber. They carried out a conjugate analysis and presented temperature contours within the vane material, but no heat transfer coefficients at the vane surface.

He et al. (1995) analyzed a semi-circular leading edge with four rows of laterally-inclined film cooling holes positioned symmetrically about the stagnation line. Periodicity in the spanwise direction and flow symmetry about the stagnation line were exploited for the computational analysis. Uniform coolant flow conditions were specified at entry to the hole-pipes with an L/D of 4 ; the coolant plenum was not gridded. The predicted film cooling effectiveness compared reasonably with experimental data for a DR of unity. Subsequently, He et al. (1996) repeated the analysis for a DR of 1.5. 
However, their interest was not in the hole-exit profiles.

In a blind test study, Martin and Thole (1997), Lin et al. (1997), and Thakur et al. (1997) analyzed leading-edge film cooling with compound angle injection on a circular cylinder with two rows of staggered film-cooling holes located at the stagnation location and at $25^{\circ}$. The spanwise injection angle was $20^{\circ}$ and density ratio was 1.8 . While the hole-pipes and plenum were gridded, emphasis was on comparing the predicted adiabatic effectiveness on the cylinder surface with experimental data of Cruse et al. (1997). Martin and Thole (1997) used an unstructured commercial package offered by Fluent, Inc. that is unable to yield accurate heat transfer coefficients at the surface. Lin et al. (1997) used a cell-centered finite-volume code with the $k$ - $\omega$ model of Wilcox (1994), while Thakur et al. (1997) used an in-house code based on a pressure correction algorithm. For the cylinder, symmetry at the stagnation line was exploited by all analyses. On a real blade, however, the pressure and suction surfaces behave differently even in the shower-head region, specially when the dynamic stagnation point does not coincide with the geometric one.

The above survey indicates that the interaction between the film coolant flow and the mainstream over an actual blade surface is not well understood even though it is known to have a large influence on the heat transfer characteristics of film-cooled blades (Garg and Gaugler, 1997b). We need to model this interaction in order to incorporate three-dimensional analysis in the design phase of a filmcooled blade. Herein, we analyze in detail the coolant flow structure issuing out of three staggered rows of compound-angled holes on a real blade, and its interaction with the mainstream, using a multi-block Navier-Stokes code.

\section{ANALYSIS}

Briefly, the code, TRAF3D.MB (Steinthorsson et al., 1993, 1997), is an explicit, multigrid, cell-centered, finite volume code with a $k-\omega$ turbulence model without any wall functions. This is a general purpose flow solver designed for simulations of flows in complicated geometries. The Navier-Stokes equations in a rotating Cartesian coordinate system are mapped onto a general body-fitted coordinate system using standard techniques. The multistage Runge-Kutta scheme developed by Jameson et al. (1981) is used to advance the flow solution in time from an initial approximation to the steady state. A spatially varying time step along with a CFL number of 4 is used to speed convergence to the steady state. Eigenvalue-scaled artificial dissipation and variable-coefficient implicit residual smoothing are used along with a full-multigrid method. The overall accuracy of the code is second order. A single-block version of the same code, modified for film-cooling applications, was used by Garg and co-workers for the film cooling studies described earlier. The $k-\omega$ model of Wilcox (1994) with Menter's modifications (Menter, 1993) has yielded good results for heat transfer on film-cooled blades (Garg and Ameri, 1997; Garg, 1997c), and is highly desirable for multi-block codes since it does not require the computation of distance from a wall. Also, no wall functions are used, thus avoiding any bias to the complex interactions between the coolant and the mainstream near the blade surface.

It is assumed that the effective viscosity for turbulent flows can be written as

$$
\mu_{e f}=\mu_{t}+\mu_{T}
$$

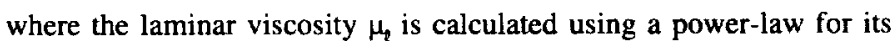
dependence on temperature. The turbulent viscosity $\mu_{\mathrm{T}}$ is computed using the $k$ - $\omega$ model described by Rigby et al. $(1996,1997 \mathrm{a})$ and Ameri et al. (1997). The turbulent thermal diffusivity is computed from

$$
\alpha_{T}=\frac{\mu_{T}}{\rho \operatorname{Pr}_{T}}
$$

where a constant value of 0.9 is used for the turbulent Prandtl number, $\operatorname{Pr}_{\mathrm{T}}$.

\section{Boundary Conditions}

At the main flow inlet boundary located at an axial distance equal to $80 \%$ of the blade axial chord upstream of the blade leading edge, the total temperature, total pressure, whirl, and meridional flow angle are specified, and the upstream-running Riemann invariant based on the total absolute velocity is calculated at the first interior point and extrapolated to the inlet. The velocity components are then decoupled algebraically, and the density is found from total temperature, total pressure and total velocity using an isentropic relation. For the turbulence model, the value of $k$ and $\omega$ is specified using the experimental conditions, namely

$$
k=1.5\left(u_{i n} T u_{i n}\right)^{2}, \quad \omega=k^{1 / 2} / \ell,
$$

where $T u_{\mathrm{in}}$ is the intensity of turbulence at the inlet (taken to be 0.052 as per experimental data for the VKI rotor), $u_{\text {in }}$ is the inlet velocity, and $\ell$ is the turbulence length scale representing the size of the energy containing eddies. This length scale is usually not reported as part of the experimental conditions, and needs to be assumed. For the present study, $\ell$ was assumed to be $5 \%$ of the blade axial chord. Similar considerations hold for the inlet to the plenum. It may be noted that Garg and Ameri (1997) found negligible difference in the heat transfer coefficient at the surface of a film-cooled blade under similar mainstream conditions when $T u_{\text {in }}$ was raised to 0.15 , and $\ell$ was taken to be 0.01 or 0.25 at the inlet, using the $k-\varepsilon$ model. It is expected that a similar conclusion holds for the $k-\omega$ model as well.

At the main flow exit plane located at an axial distance equal to the $70 \%$ of the blade axial chord downstream of the blade trailing edge, the static pressure is specified and the density and velocity components are extrapolated from the interior. The exit plane of the plenum is treated similarly. At the solid surfaces of the blade, plenum and hole-pipes, the no-slip condition is enforced, and temperature is specified as per experimental data. The boundary conditions for turbulence quantities on the walls are $k=0$, and

$$
\omega=\left.100 \frac{\partial u}{\partial y}\right|_{\text {wall }}
$$

for a hydraulically smooth surface. An upper limit is imposed on the value of $\omega$ at the wall, as suggested by Menter (1993) and found effective by Chima (1996),

$$
\left(\omega_{\max }\right)_{\text {mall }}=\frac{800}{\operatorname{Re}} \frac{v}{(\Delta y)^{2}}
$$

The grid around the blade extends to mid-way between two adjacent blades with periodic flow conditions in terms of cylindrical velocity components set on a dummy grid line outside this boundary. For a linear cascade (which is true for the VKI rotor experiments), it is possible to consider only a part (equal to one spanwise pitch of the holes) of the real span for computational purposes with periodic boundary conditions at either end of this computational span for the main flow. Since the coolant flow through the plenum is 
predominantly radial, we have to impose a pressure drop across the inlet and exit of the plenum in order to ensure required coolant flow through the hole-pipes. The total temperature of the coolant in the plenum is known from the experimental data, and is specified as such at inlet to the plenum.

\section{BLADE AND EXPERIMENTAL DETAILS}

The experimental data on the VKI rotor with three staggered rows of shower-head cooling holes have been provided by Camci and Arts (1985), using the short-duration VKI Isentropic Compression Tube facility. Figure 1 shows the VKI rotor geometry along with cooling hole details. Three staggered rows of cylindrical cooling holes $(d=$ $0.8 \mathrm{~mm} ; \mathrm{s} / \mathrm{c}=-0.031,0,0.031)$ were located around the leading edge. The row and hole spacings were both $2.48 \mathrm{~mm}$. These holes were spanwise angled at $30^{\circ}$ from the tangential direction and drilled in a plane perpendicular to the blade surface. The blade instrumented for heat flux measurements was milled from 'Macor' glass ceramic and 45 platinum thin films were applied on its surface. One cylindrical cavity of $4.5 \mathrm{~mm}$ diameter was drilled along the blade height to act as the plenum chamber, as shown in Fig. 1. The local wall convective heat flux was deduced from the corresponding time-dependent surface temperature evolution, provided by the platinum thin-film gages. The wall temperature/wall heat flux conversion was obtained from an electrical analogy, simulating a one-dimensional semi-infinite body configuration. More details are available in Camci and Arts (1985).

\section{COMPUTATIONAL DETAILS}

Before the flow solver can be used, the flow domain has to be gridded. The compound-angled shower-head holes present the greatest challenge due to the acute angle ( $30^{\circ}$ here) with the spanwise direction. For a real blade, the plenum extends radially from the hub towards the blade tip with bleed off of the coolant through the holes. A grid has been generated for the same configuration for the three staggered rows of shower-head holes on the VKI rotor, using the commercial code GridPro/az3000 (Program Development Corporation, 1997). The grid covers the inside of the plenum and hole-pipes for the coolant flow, and the outside of the blade for the main flow.

Some details of the inviscid grid are shown in Fig. 2. It may be noted that the flow solver is run on the viscous grid; the inviscid grid is shown here only for clarity. The viscous grid is obtained from the inviscid grid by clustering the grid near all the solid walls. The clustering is done in such a way as to ensure that in the viscous grid, the distance of any cell center adjacent to a solid wall, measured in wall units $\left(\mathrm{y}^{+}\right)$, is less than unity for the cases studied here, following Boyle and Giel (1992). Details of the inviscid grid on the plenum, the hole-pipes and the blade surface are shown in Fig. 3. As can be observed from Fig. 3, the grid quality is very good even near the sharp corners at the intersection of hole-pipe and blade or plenum. Initially, the grid consists of 192 blocks but before the solver is used, it can be merged into just 36 blocks using the Method of Weakest Descent (Rigby, 1996; Rigby et al., 1997b). The final viscous grid consists of a total of 150528 cells, with 16896 cells in each of the three holepipes, and 25216 cells within the plenum. For computational accuracy the ratio of two adjacent grid sizes in any direction was kept within 0.8-1.25. We may point out that using the commercial code GridPro/az3000, two multi-block grids were first generated for the uncooled VKI rotor for a grid independence study. One grid had 1.7 times as many cells as in the second grid. The two grids yielded nearly identical heat transfer coefficient and pressure distributions at the blade surface. It was also found that a multi-block viscous grid with a total of 72704 cells gave the same heat transfer coefficient (within $\pm 2 \%$ ) on the blade surface as reported by Garg and Ameri (1997) using a single-block C-grid with 292864 cells. This brings out clearly a virtue of the multi-block grid. We may also note that the multi-block grid has better quality and provides a much finer resolution near and over the hole exits than the single-block C-grid. Computations were run on the 16-processor $\mathrm{C} 90$ supercomputer at NASA Ames Research Center. The code requires about $18 \mathrm{Mw}$ of storage with all blocks in memory, and takes about $12.5 \mathrm{~s}$ per iteration for two levels of multi-grid. A case requires about 1200 iterations to converge.

\section{RESULTS AND DISCUSSION}

Four experimental cases for the VKI rotor were analyzed for comparison. The values of various parameters for these cases are given in Table 1 . These cases cover a wide range of coolant mass flow rate from $0.5 \%$ to $1.01 \%$ of the main flow rate, and ratio of coolant temperature to mainstream stagnation temperature from 0.49 to 0.59 . Figure 4 compares the span-averaged heat transfer coefficient on the cooled blade surface with the experimental data of Camci and Arts (1985), denoted by squares, for the case 155. The abscissa in this and Figs. 5-7 represents the surface distance along the blade normalized by the true chord, as per the experimental data of Camci and Arts (1985). The three short vertical lines at the bottom of this and Figs. 5-7 denote the location of shower-head cooling rows. Also shown in Figs. 4 and 5 is the blade heat transfer coefficient predicted by the analysis of Garg and Ameri (1997) using $k$ - $\omega$ model wherein, following Leylek and Zerkle (1994), 1/7th power-law distribution for the coolant velocity and temperature at the hole exits was specified, and the region inside the hole-pipes and plenum was not included in the computations. We may point out that Garg and Ameri (1997) compared the heat transfer coefficient on the VKI rotor corresponding to all six rows of cooling holes, not just the three rows of shower-head holes considered here. Thus for the dashed-line results in Figs. 4 and 5 , the old code was specifically re-run for cases 155 and 154 . The superiority of the present results is clearly evident on the suction surface of the blade, while on the pressure surface, both analyses yield equally good comparison with the experimental data. As we will see, the coolant velocity and temperature distributions at any of the hole exits are different from the $1 / 7$ th power-law. It does appear, however, that there is negligible effect of coolant velocity and temperature distributions at the hole exit on the heat transfer coefficient on the blade pressure surface, but on the suction surface, the effect is considerable.

Figure 5 shows similar results for the case 154, while Figs. 6 and 7 show the comparison only between the present results and the experimental data for cases 157 and 120 , respectively. Predictions by the analysis of Garg and Ameri (1997) are not shown in Figs. 6 and 7, since the old (single-block) code was not run for these cases. A comparison of the predicted heat transfer coefficient in the leading edge region between the rows of shower-head holes is not possible due to the lack of experimental data in this narrow region. The experimental uncertainty in the measurement of heat transfer coefficient is about 5\% except in the shower-head region where it is estimated to be as high as $10-15 \%$ (Camci and Arts, 1985). This may partially account for the somewhat poor comparison in the leadingedge region on the pressure side.

It may be pointed out that Camci and Arts (1985) do not provide 
a value for the temperature of plenum and hole-pipe walls. The value for $T_{w} / T_{0}$, listed in Table 1 , pertains to the blade surface temperature. The code was therefore run twice for each of the four cases; once with all wall temperatures having the value listed in Table 1 for $T_{w} / T_{0}$, and again for plenum and hole-pipe walls assumed to be at the value listed in Table 1 for $T / T_{0}$. In the former case, the coolant bulk temperature did rise by about $3-8 \%$, depending on the case, in passing through the hole-pipe. This results in about $5 \%$ difference in the heat transfer coefficient at the blade surface between the two runs. This difference is within the experimental uncertainty of Camci and Arts (1985) data. Figures 4-7 show the blade heat transfer coefficient when all wall temperatures have the same value as $T_{w} / T_{0}$ in Table 1 .

We now look at the details of flow at and near the cooling hole exits. Figure 8 shows the normalized velocity and temperature contours at the shower-head hole exits on the blade surface for the case 155. For the velocity contours shown at an interval of 0.1 , the magnitude of coolant velocity through the hole exit is normalized with respect to its average value, $\mathrm{V}_{\mathrm{av}}$, over the hole exit, while for the temperature contours, also shown at an interval of 0.1 , the ratio, $\left(\mathrm{T}_{w}\right.$ $T) /\left(T_{w}-T_{a v}\right)$, is plotted, where $T_{a v}$ is the average temperature over the hole exit. The values of $\mathrm{V}_{\mathrm{av}}$ and $\mathrm{T}_{\mathrm{av}}$ are given in Table 2 . In order to understand the figure better, assume the main flow to approach the centerline of the figure along the normal direction as if approaching the leading edge of the blade, and then spread out on the left and right sides like the main flow bifurcating over the suction and pressure surfaces of the blade. Moreover, the contours are shown as if looking directly into the hole exit. From these contours, it is clear that the coolant flow at the exit plane of the leading edge hole, $M$, is deflected toward the suction side (due to the dynamic stagnation point located on the pressure side, as we will see), and the coolant flow at the exit plane of the other two holes, $P$ on the pressure side and $S$ on the suction side, is deflected considerably in the direction of the main flow at these locations, as we will observe shortly. Moreover, the velocity and temperature profiles at the exit plane of the holes do not follow the $1 / 7$ th power-law distribution that Leylek and Zerkle's analysis for a flat plate configuration (Leylek and Zerkle, 1994) would indicate for L/D $\geq 3.0$. For the VKI rotor $\mathrm{L} / \mathrm{D} \approx 6$ for the shower-head holes. The hole exit-plane profiles are more like higher-order polynomials, with considerable skewness for the $P$ and $S$ holes. It may be noted that $1 / 7$ th power-law profile yields a value of 1.224 for the ratio of maximum to average velocity, while here we have a value about 1.3 for all holes. Similarly, for the temperature distribution, the $1 / 7$ th power-law would yield a maximum value of 1.2 for the ratio plotted, while we have a value about 1.4 for all holes.

For the same case 155, Fig. 9 shows the contours for $\rho k$ and $\rho \omega$ at intervals of 0.0002 and 100 , respectively, at the exit plane of the holes $\mathrm{M}, \mathrm{P}$ and $\mathrm{S}$ in a setting similar to that for Fig. 8. The profiles are again skewed in the direction of the main flow over the holes $P$ and $S$. However, $\rho \omega$ appears to be almost uniform over much of the hole exit-plane, except for the boundary layer effect near the hole-pipe wall.

In order to understand the interaction of coolant flow with the mainstream, Fig. 10 shows the velocity vectors near the blade leadingedge region for case 155 . The intense mixing of the coolant and mainstream flows is evident. Also, the dynamic stagnation point is designated by $S$ on the figure, and occurs on the pressure side of the blade, in conformity with the experimental observation (Camci and Arts, 1985). It may be noted that the leading-edge hole $M$ is located at the geometric stagnation point. Thus, holes $\mathrm{M}$ and $\mathrm{S}$ contribute towards cooling the suction surface while only hole $P$ contributes on the pressure surface. Details of the coolant flow exiting the holes on the blade side are shown in Fig. 11 on a lateral section containing the hole centerline for the case 155 . While the coolant flow from hole $M$ is only slightly deflected towards the suction side by the mainstream, the influence of the mainstream on the coolant flow exiting holes $P$ and $S$ is clearly evident. This gives rise to the highly skewed distribution of velocity, temperature, $k$ and $\omega$ of the coolant at the exit of holes $P$ and $S$. Figure 12 shows the coolant flow entering the holepipes from the plenum for the case 155 on the same lateral section as for Fig. 11. While the coolant enters the hole-pipe $M$ as expected, there is a more pronounced low-momentum region, but no separation, at entry to hole-pipes $P$ and $S$ on the side away from the hole-pipe $M$. Note that only about half of hole-pipes $P$ and $S$ are shown in Fig. 12 for the sake of clarity. Due to the long length of the hole-pipes, (L/D $\approx 6$ ), the coolant flow straightens out in the hole-pipes before it exits on the blade side, as shown in Fig. 11.

For the various cases analyzed, Table 2 lists the distribution of coolant mass flow through each hole-pipe, and average velocity and temperature for the coolant flow at the exit of each hole on the blade side. As can be observed from Table 2, the coolant flow through the hole $M$ is the smallest while that through hole $S$ is the largest. This is due to the smallest pressure drop across the hole-pipe $M$ and the largest across the hole-pipe $S$. Unfortunately, the experimental distribution of coolant mass flow through each hole-pipe is not available for comparison. Table 3 lists the ratio of coolant mass as well as momentum flux at the exit of each hole on the blade side to that for the main flow at inlet to the blade. These provide the reader a frame of reference.

\section{CONCLUSIONS}

The significance of within-hole and near-hole physics in relation to heat transfer on a film-cooled blade has been studied by following the coolant flow through the plenum and hole-pipes for the three rows of shower-head holes on the VKI rotor. Wilcox's $k$ - $\omega$ turbulence model is used. The present study provides a much better comparison for the span-averaged heat transfer coefficient on the blade surface with the experimental data than an earlier analysis wherein coolant velocity and temperature distributions were specified at the hole exits rather than extending the computational domain into the hole-pipe and plenum. Detailed distributions of coolant velocity, temperature, $k$ and $\omega$ at the hole exits are also presented. It is found that the coolant velocity and temperature distributions at the hole exit on the blade side do not follow the $1 / 7$ th power-law profile, and are highly skewed by the mainstream flow for the holes $P$ and $S$. Distributions of $k$ and $\omega$ at the exit of holes $P$ and $S$ are also skewed. The dynamic stagnation point is found to lie between holes $M$ and $P$, leading to the largest coolant mass flow through the hole $S$ and the smallest through the hole M.

\section{ACKNOWLEDGEMENTS}

The authors wish to thank Dr. Raymond Gaugler, Chief, Turbine Branch, and Mr. John Rohde of the Subsonic Systems Office at the NASA Lewis Research Center for their support of this work.

\section{REFERENCES}

Ameri, A.A., Steinthorsson, E. and Rigby, D.L., 1997, Effect of Squealer Tip on Rotor Heat Transfer and Efficiency, ASME Paper 97GT-128. 
Berhe, M.K. and Patankar, S.V., 1996, A Numerical Study of Discrete-Hole Film Cooling, ASME Paper 96-WA/HT-8.

Berhe, M.K. and Patankar, S.V., 1997, Computation of DiscreteHole Film Cooling: A Hydrodynamic Study, ASME Paper 97-GT-80.

Bohn, D.E., Becker, V.J. and Rungen, A.U., 1997, Experimental and Numerical Conjugate Flow and Heat Transfer Investigation of a Shower-Head Cooled Turbine Guide Vane, ASME Paper 97-GT-15.

Boyle, R.J. and Giel, P., 1992, Three-Dimensional Navier Stokes Heat Transfer Predictions for Turbine Blade Rows, AlAA Paper 923068.

Brittingham, R.A. and Leylek, J.H., 1997, A Detailed Analysis of Film-Cooling Physics Part IV: Compound-Angle Injection with Shaped Holes, ASME Paper 97-GT-272.

Burd, S.W., Kaszeta, R.W. and Simon, T.W., 1996, Measurements in Film Cooling Flows: Hole L/D and Turbulence Intensity Effects, ASME Paper 96-WA/HT-7.

Burd, S.W. and Simon, T.W., 1997, The Influence of Coolant Supply Geometry on Film Coolant Exit Flow and Surface Adiabatic Effectiveness, ASME Paper 97-GT-25.

Camci, C. and Arts, T., 1985, Experimental Heat Transfer Investigation Around the Film-Cooled Leading Edge of a HighPressure Gas Turbine Rotor Blade, J. Eng. Gas Turbines \& Power, Vol. 107, pp. 1016-1021.

Chima, R.V., 1996, A $k$ - $\omega$ Turbulence Model for Quasi-ThreeDimensional Turbomachinery Flows, AIAA Paper 96-0248.

Cruse, M.W., Yuki, U.M. and Bogard, D.G., 1997, Investigation of Various Parametric Influences on Leading Edge Film Cooling, ASME Paper 97-GT-296.

Garg, V.K., 1997a, Adiabatic Effectiveness and Heat Transfer Coefficient on a Film-Cooled Rotating Blade, Numer. Heat Transfer, Part A, Vol. 32, pp. 811-830.

Garg, V.K., 1997b, Comparison of Predicted and Experimental Heat Transfer on a Film-Cooled Rotating Blade Using a Two-Equation Turbulence Model, ASME Paper 97-GT-220.

Garg, V.K., 1997c, Heat Transfer on a Film-Cooled Rotating Blade Using Different Turbulence Models, submitted.

Garg, V.K. and Abhari, R.S., 1997, Comparison of Predicted and Experimental Nusselt Number for a Film-Cooled Rotating Blade, Int. J. Heat \& Fluid Flow, Vol. 18, pp. 452-460.

Garg, V.K. and Ameri, A.A., 1997, Comparison of Two-Equation Turbulence Models for Prediction of Heat Transfer on Film-Cooled Turbine Blades, Numer. Heat Transfer, Part A, Vol. 32, pp. 347-371.

Garg, V.K. and Gaugler, R.E., 1993, Heat Transfer in FilmCooled Turbine Blades, ASME Paper 93-GT-81.

Garg, V.K. and Gaugler, R.E., 1994, Prediction of Film Cooling on Gas Turbine Airfoils, ASME Paper 94-GT-16.

Garg, V.K. and Gaugler, R.E., 1996, Leading Edge Film Cooling Effects on Turbine Blade Heat Transfer, Numer. Heat Transfer, Part A, Vol. 30, pp. 165-187.

Garg, V.K. and Gaugler, R.E., 1997a, Effect of Coolant Temperature and Mass Flow on Film Cooling of Turbine Blades, Int. J. Heat Mass Transfer, Vol. 40, pp. 435-445.

Garg, V.K. and Gaugler, R.E., 1997b, Effect of Velocity and Temperature Distribution at the Hole Exit on Film Cooling of Turbine Blades, J. Turbomachinery, vol. 119, pp. 343-351.

Giebert, D., Gritsch, M., Schulz, A. and Wittig, S., 1997, FilmCooling from Holes with Expanded Exits: A Comparison of Computational Results with Experiments, ASME Paper 97-GT-163.

Goldstein, R.J., 1971, Film Cooling, Advances in Heat Transfer,
Vol. 7, pp. 321-379, Academic.

He, P., Licu, D., Salcudean, M. and Gartshore, I.S., 1996, Leading Edge Film Cooling: Computations and Experiments including Density Effects, ASME Paper 96-GT-176.

He, P., Salcudean, M. and Gartshore, I.S., 1995, Computations of Film Cooling for the Leading Edge Region of a Turbine Blade Model, ASME Paper 95-GT-20.

Hyams, D.G. and Leylek, J.H., 1997, A Detailed Analysis of Film-Cooling Physics Part III: Streamwise Injection with Shaped Holes, ASME Paper 97-GT-271.

Jameson, A., Schmidt, W. and Turkel, E., 1981, Numerical Solutions of the Euler Equations by Finite Volume Methods Using Runge-Kutta Time-Stepping Schemes, AlAA Paper 81-1259.

Leylek, J.H. and Zerkle, R.D., 1994, Discrete-Jet Film Cooling: A Comparison of Computational Results with Experiments, $J$. Turbomachinery, Vol. 116, pp. 358-368.

Lin, Y.-L., Stephens, M.A. and Shih, T.I-P., 1997, Computation of Leading-Edge Film Cooling with Injection Through Rows of Compound-Angle Holes, ASME Paper 97-GT-298.

Martin, C.A. and Thole, K.A., 1997, Leading Edge Film-Cooling with Compound Angle Injection, ASME Paper 97-GT-297.

McGovern, K.T. and Leylek, J.H., 1997, A Detailed Analysis of Film-Cooling Physics Part II: Compound-Angle Injection with Cylindrical Holes, ASME Paper 97-GT-270.

Menter, F.R., 1993, Zonal Two-Equation $k$ - $\omega$ Turbulence Models for Aerodynamic Flows, AlAA Paper 93-2906.

Pietrzyk, J.R., Bogard, D.G. and Crawford, M.E., 1989, Experimental Study of the Interaction of Dense Jets With a Crossflow for Gas Turbine Applications, Rep. No. 89-1, ME Dept., Univ. of Texas at Austin.

Program Development Corporation, 1997, "GridPro ${ }^{\mathrm{TM}} / \mathrm{az} 3000$ User's Guide and Reference Manual," White Plains, NY.

Rigby, D.L., 1996, Method of Weakest Descent for Automatic Block Merging, Proc. 15th Intern. Conf. on Numer. Methods in Fluid Dynamics, Monterey, CA.

Rigby, D.L., Ameri, A.A. and Steinthorsson, E., 1996, Internal Passage Heat Transfer Prediction Using Multiblock Grids and a $k-\omega$ Turbulence Model, ASME Paper 96-GT-188.

Rigby, D.L., Steinthorsson, E. and Ameri, A.A., 1997a, Numerical Prediction of Heat Transfer in a Channel with Ribs and Bleed, ASME Paper 97-GT-431.

Rigby, D.L., Steinthorsson, E. and Coirier, W.J., 1997b, Automatic Block Merging Using the Method of Weakest Descent, AIAA Paper 97-0197.

Steinthorsson, E., Ameri, A.A. and Rigby, D.L., 1997, TRAF3D.MB - A Multi-Block Flow Solver for Turbomachinery Flows, AlAA Paper 97-0996.

Steinthorsson, E., Liou, M.S. and Povinelli, L.A., 1993, Development of an Explicit Multiblock/Multigrid Flow Solver for Viscous Flows in Complex Geometries, AIAA Paper 93-2380.

Thakur, S., Wright, J. and Shyy, W., 1997, Computation of a Leading-Edge Film Cooling Flow Over an Experimental Geometry, ASME Paper 97-GT-381.

Walters, D.K. and Leylek, J.H., 1997, A Detailed Analysis of Film-Cooling Physics Part I: Streamwise Injection with Cylindrical Holes, ASME Paper 97-GT-269.

Wilcox, D.C., 1994, Simulation of Transition with a TwoEquation Turbulence Model, AIAA J., Vol. 32, pp. 247-255. 
Table 1 Parameter values for the cases analyzed

$\mathrm{M}_{\mathrm{in}}=0.251, \mathrm{M}_{\mathrm{ex}, \mathrm{s}}=0.905, \mathrm{Re}_{\mathrm{c}, \mathrm{in}}=8.42 \times 10^{5}, \mathrm{Tu}_{\mathrm{in}}=5.2 \%$

\begin{tabular}{||c|c|c|c|c|c||}
\hline case & $\mathrm{p}_{\mathrm{o}}, \mathrm{kPa}$ & $\mathrm{T}_{\mathrm{o}}, \mathrm{K}$ & $\mathrm{T}_{\mathrm{w}} / \mathrm{T}_{\mathrm{o}}$ & $\mathrm{T}_{\mathrm{c}} / \mathrm{T}_{\mathrm{o}}$ & $\mathrm{m}_{\mathrm{c}} / \mathrm{m}_{\mathrm{o}}$ \\
\hline 155 & 289.5 & 409.5 & 0.727 & 0.52 & $0.62 \%$ \\
\hline 154 & 288.3 & 408.9 & 0.722 & 0.52 & $0.50 \%$ \\
\hline 157 & 289.1 & 409.3 & 0.731 & 0.49 & $1.01 \%$ \\
\hline 120 & 292.6 & 410.3 & 0.727 & 0.59 & $0.57 \%$ \\
\hline
\end{tabular}

Table 2 Coolant mass flow distribution, average velocity and temperature

\begin{tabular}{||c|c|c|c|c|c|c|c|c|c||}
\hline \multirow{2}{*}{ case } & \multicolumn{3}{|c|}{$\begin{array}{c}\text { coolant mass flow } \\
\text { distribution }\end{array}$} & \multicolumn{2}{c|}{$\mathrm{V}_{\mathrm{av}} /\left(\mathrm{RT}_{\mathrm{o}}\right)^{1 / 2}$ at exit onto } \\
blade & \multicolumn{3}{c|}{$\mathrm{T}_{\mathrm{av}} / \mathrm{T}_{\mathrm{o}}$ at exit onto blade } \\
\cline { 2 - 10 } & Hole M & Hole P & Hole S & Hole M & Hole P & Hole S & Hole M & Hole P & Hole S \\
\hline 155 & $18.0 \%$ & $37.4 \%$ & $44.6 \%$ & 0.0573 & 0.1203 & 0.1549 & 0.601 & 0.574 & 0.560 \\
\hline 154 & $17.2 \%$ & $37.3 \%$ & $45.5 \%$ & 0.0427 & 0.0971 & 0.1284 & 0.610 & 0.580 & 0.567 \\
\hline 157 & $15.4 \%$ & $39.2 \%$ & $45.4 \%$ & 0.0770 & 0.1928 & 0.2405 & 0.588 & 0.543 & 0.531 \\
\hline 120 & $19.3 \%$ & $37.7 \%$ & $43.0 \%$ & 0.0657 & 0.1264 & 0.1546 & 0.642 & 0.621 & 0.608 \\
\hline
\end{tabular}

Table 3 Coolant mass and momentum flux ratios

\begin{tabular}{|c|c|c|c|c|c|c|}
\hline \multirow{2}{*}{ case } & \multicolumn{3}{|c|}{$(\rho \mathrm{V})_{\mathcal{C}} /(\rho \mathrm{V})_{\mathrm{m}}$} & \multicolumn{3}{c|}{$\left(\rho \mathrm{V}^{2}\right)_{\mathrm{e}} /\left(\rho \mathrm{VV}^{2}\right)_{\mathrm{m}}$} \\
\cline { 2 - 7 } & Hole M & Hole P & Hole S & Hole M & Hole P & Hole S \\
\hline 155 & 0.3801 & 0.7879 & 0.9389 & 0.1234 & 0.5376 & 0.8247 \\
\hline 154 & 0.2916 & 0.6340 & 0.7735 & 0.0860 & 0.4254 & 0.6868 \\
\hline 157 & 0.5281 & 1.3458 & 1.5583 & 0.1457 & 0.9306 & 1.3439 \\
\hline 120 & 0.3731 & 0.7301 & 0.8338 & 0.1363 & 0.5130 & 0.7165 \\
\hline
\end{tabular}

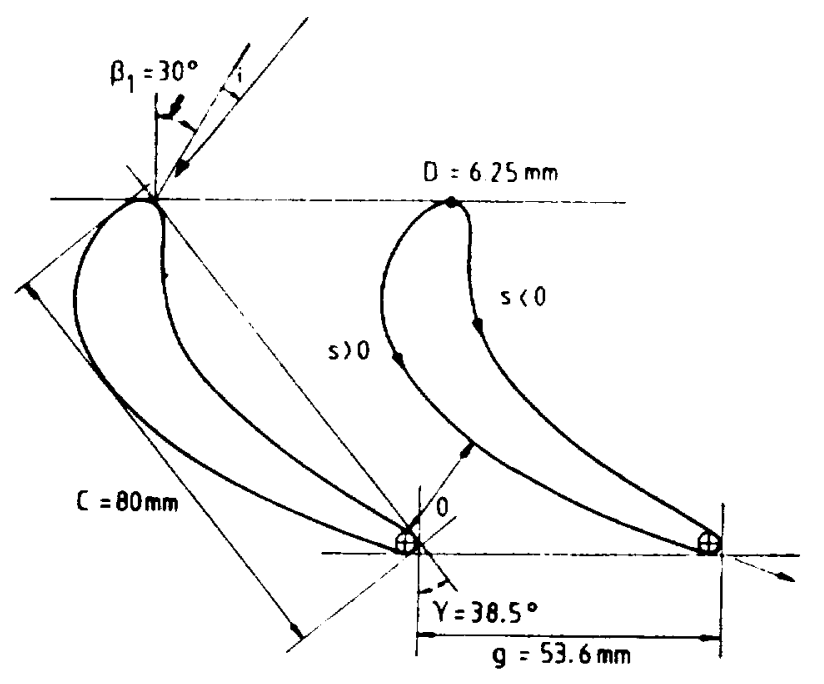

Fig. 1(a) VKI rotor

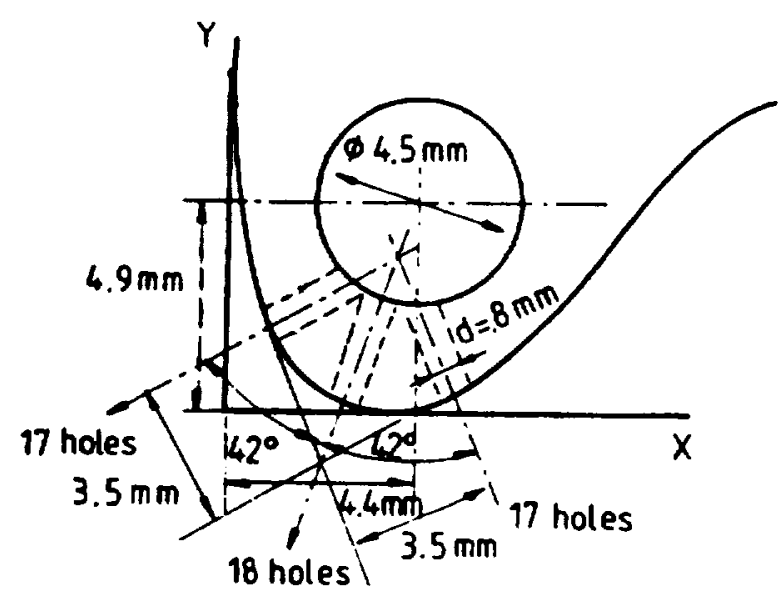

Fig. 1(b) Shower-head cooling hole details 


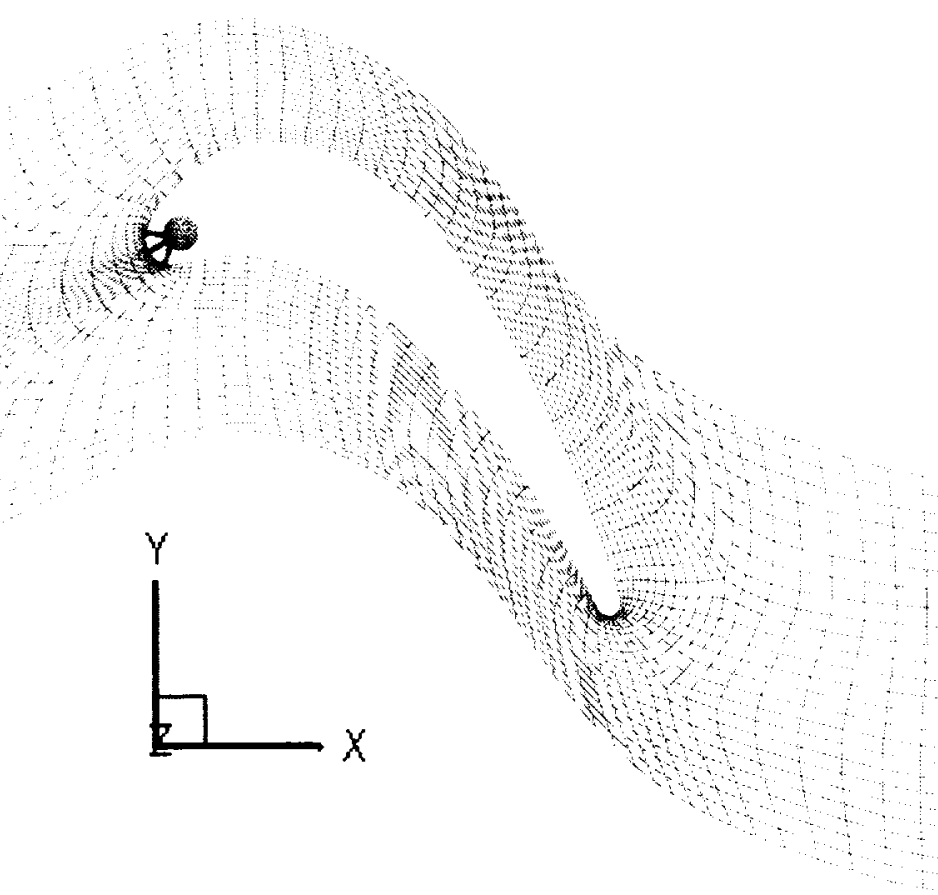

FIg. 2 Inviscid grid over the VKI rotor and withın the plenum and hole-pipes

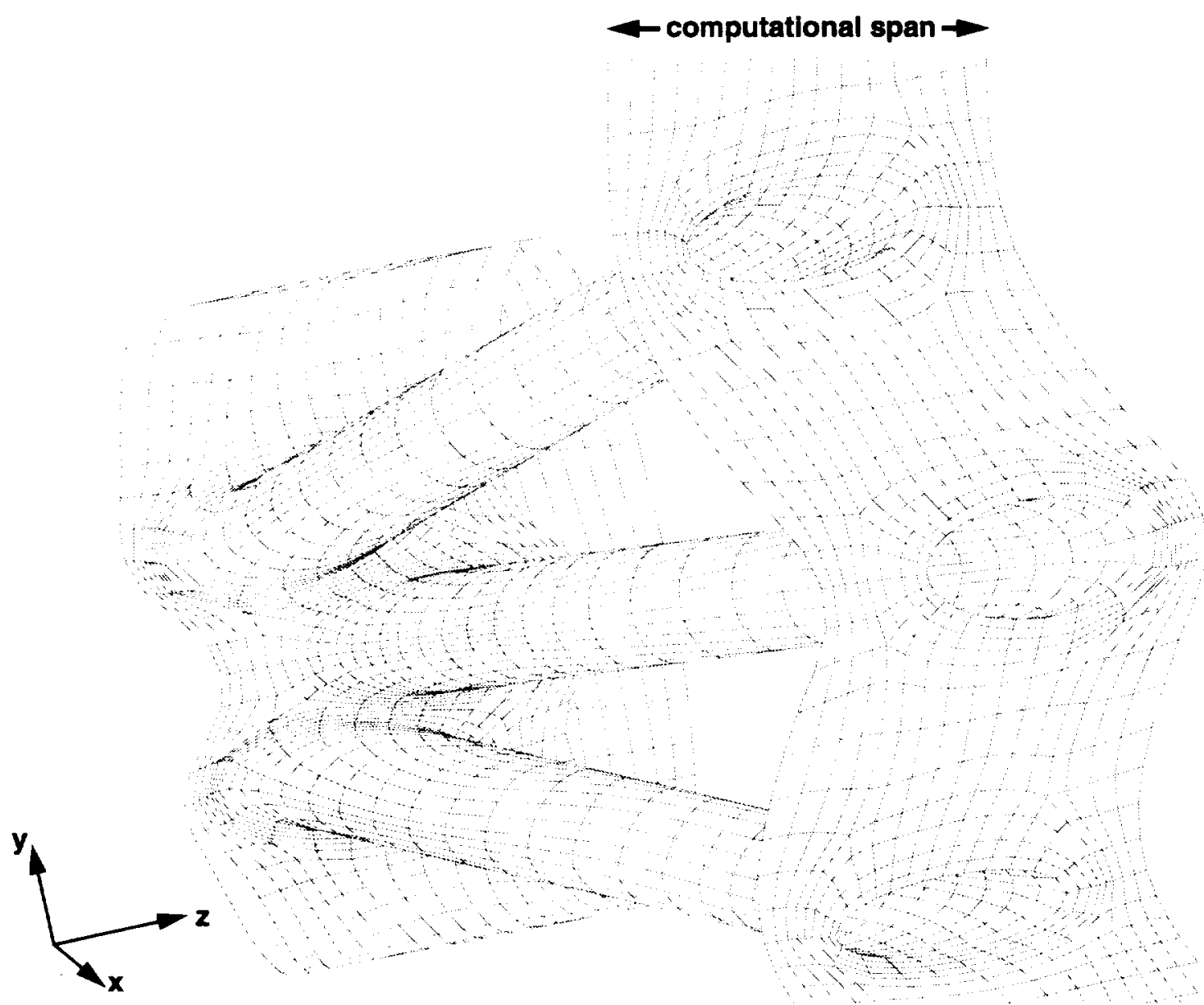

Fig. 3 Inviscid grid details on the plenum (left), the hole-pipes and the blade surface (right) 

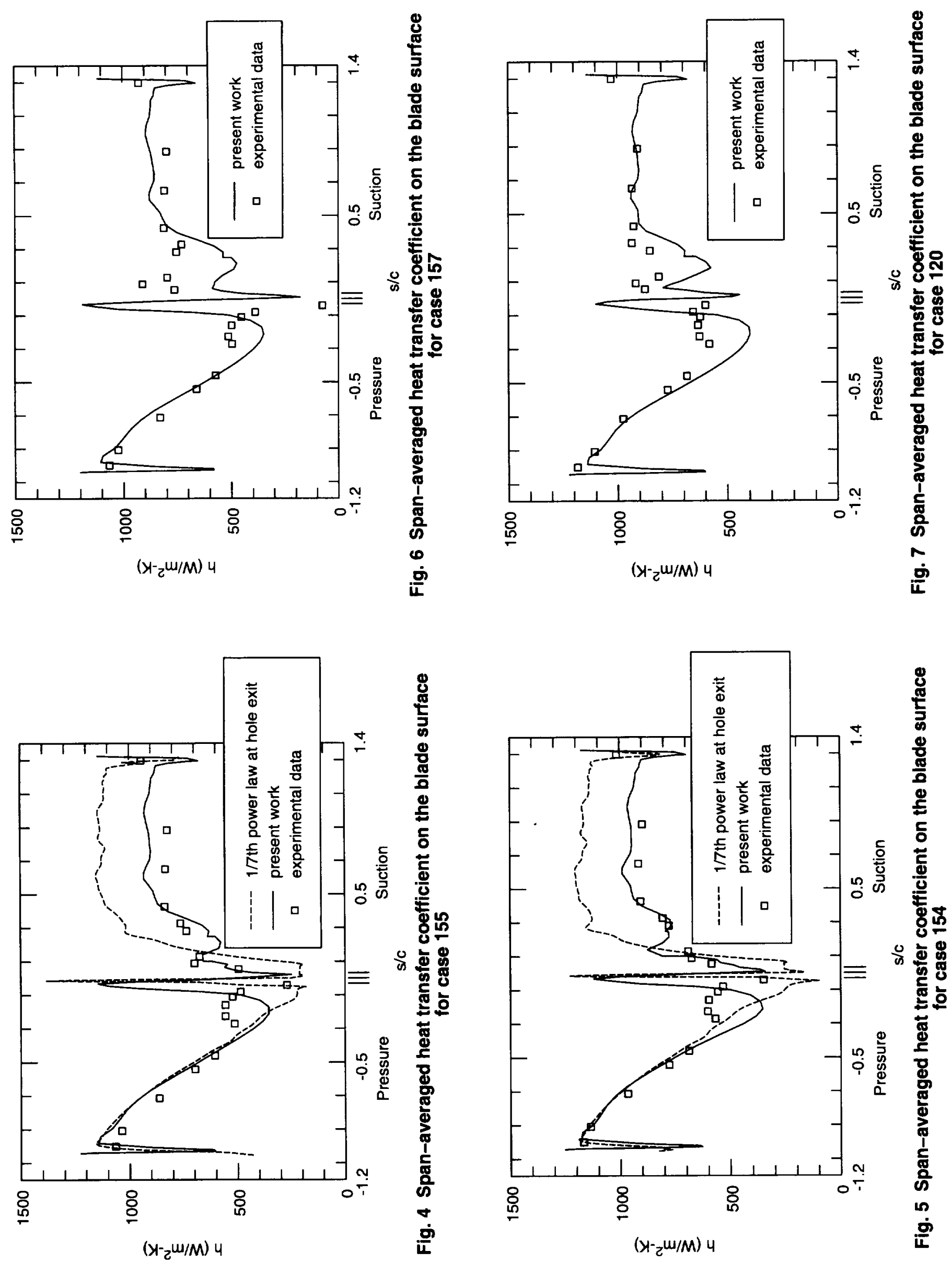

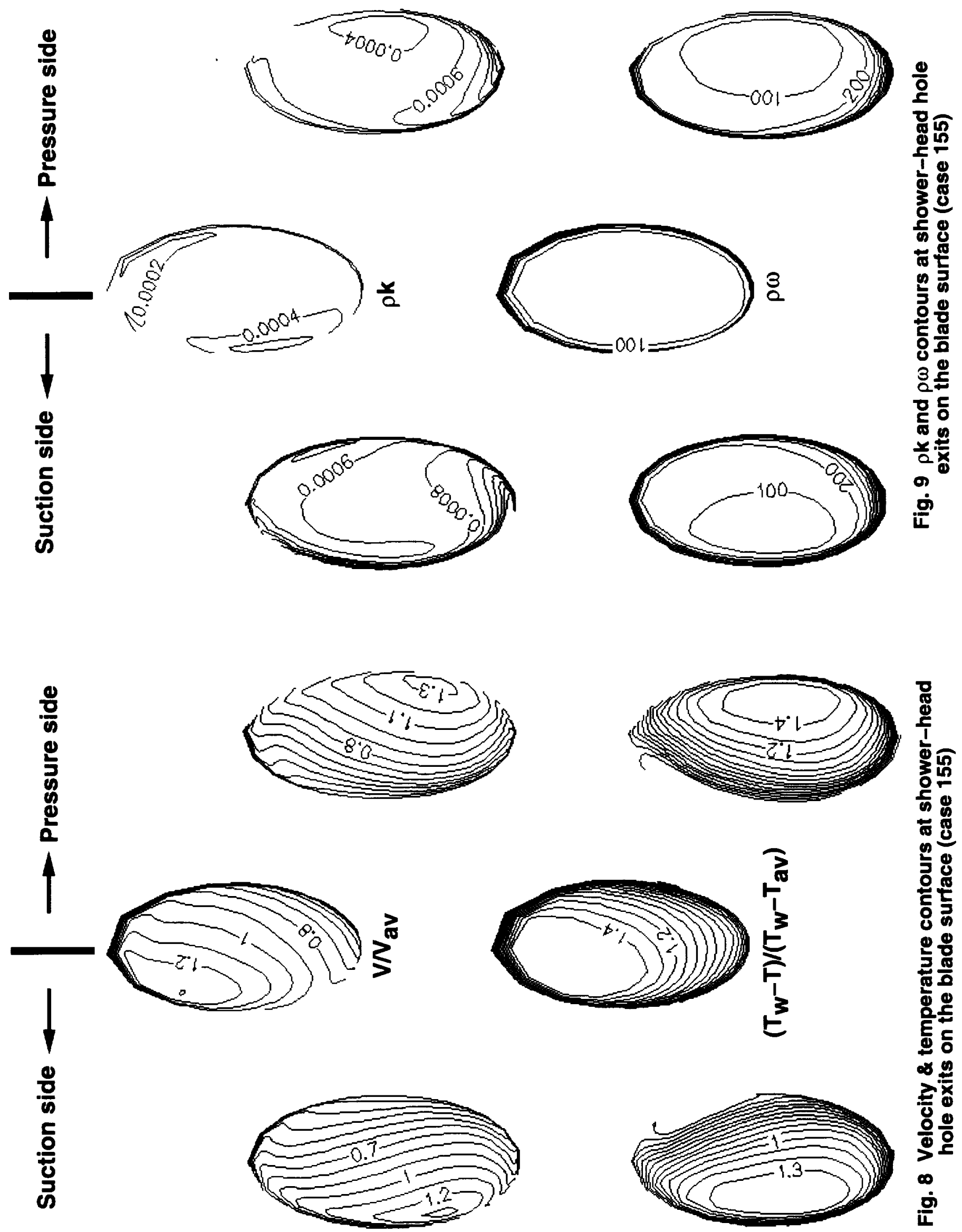


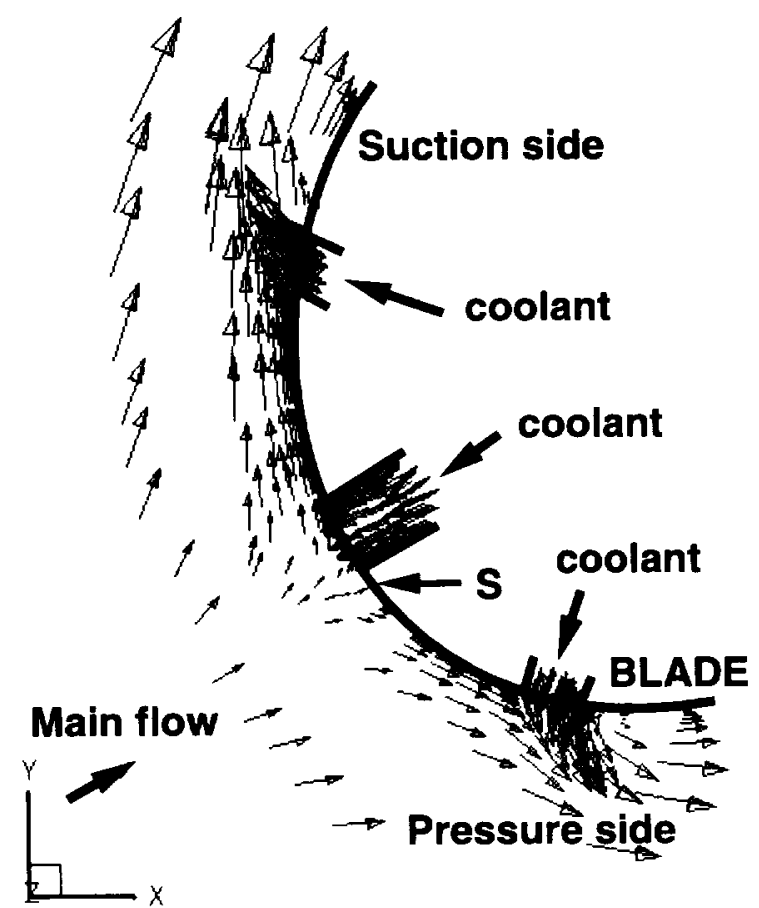

Fig. 10 Velocity vectors near the blade leading-edge region (case 155)

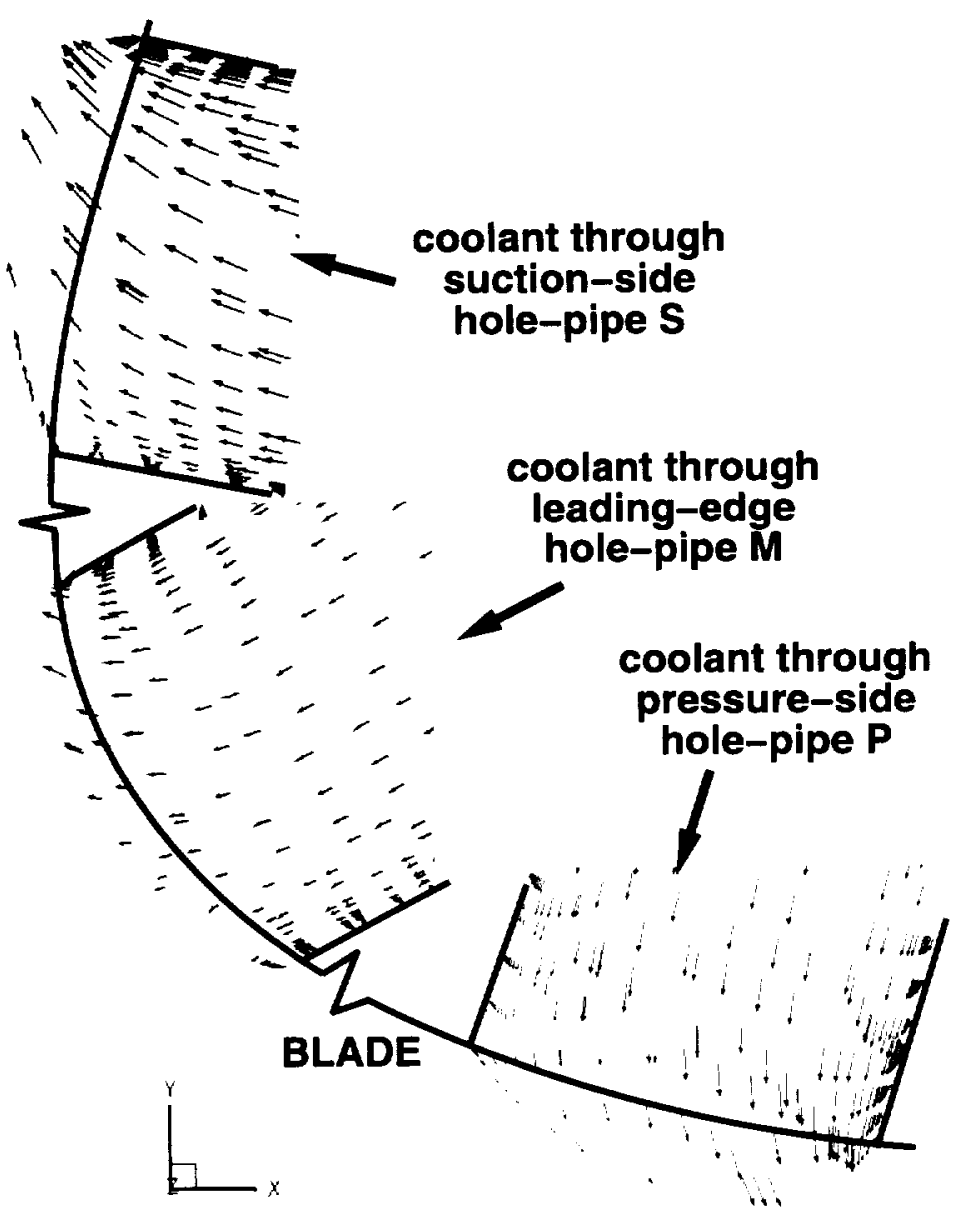

Fig. 11 Coolant velocity vectors at exit from hole-pipes onto the blade (case 155)

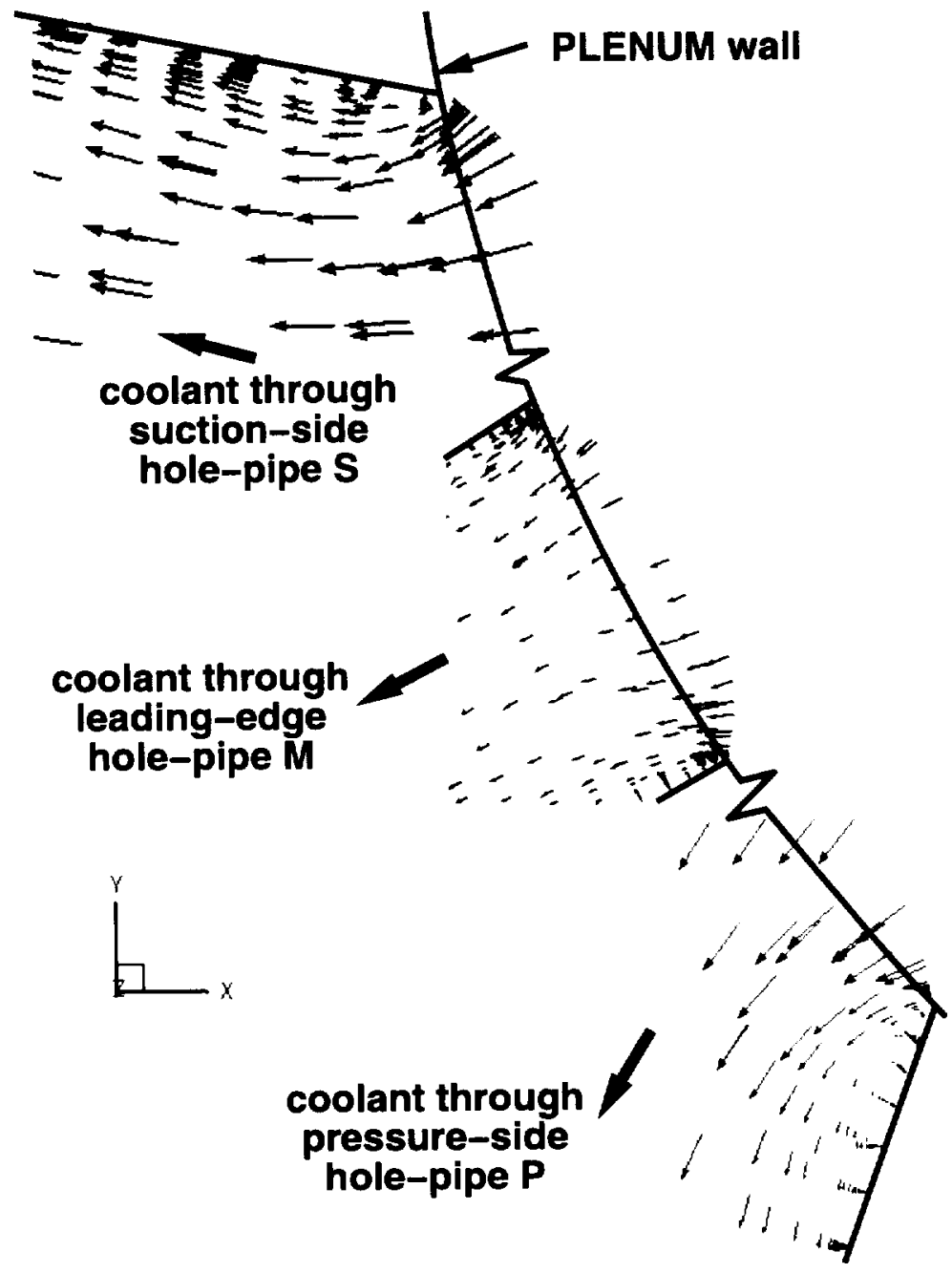

Fig. 12 Coolant velocity vectors at entrance to hole-pipes from the plenum (case 155) 


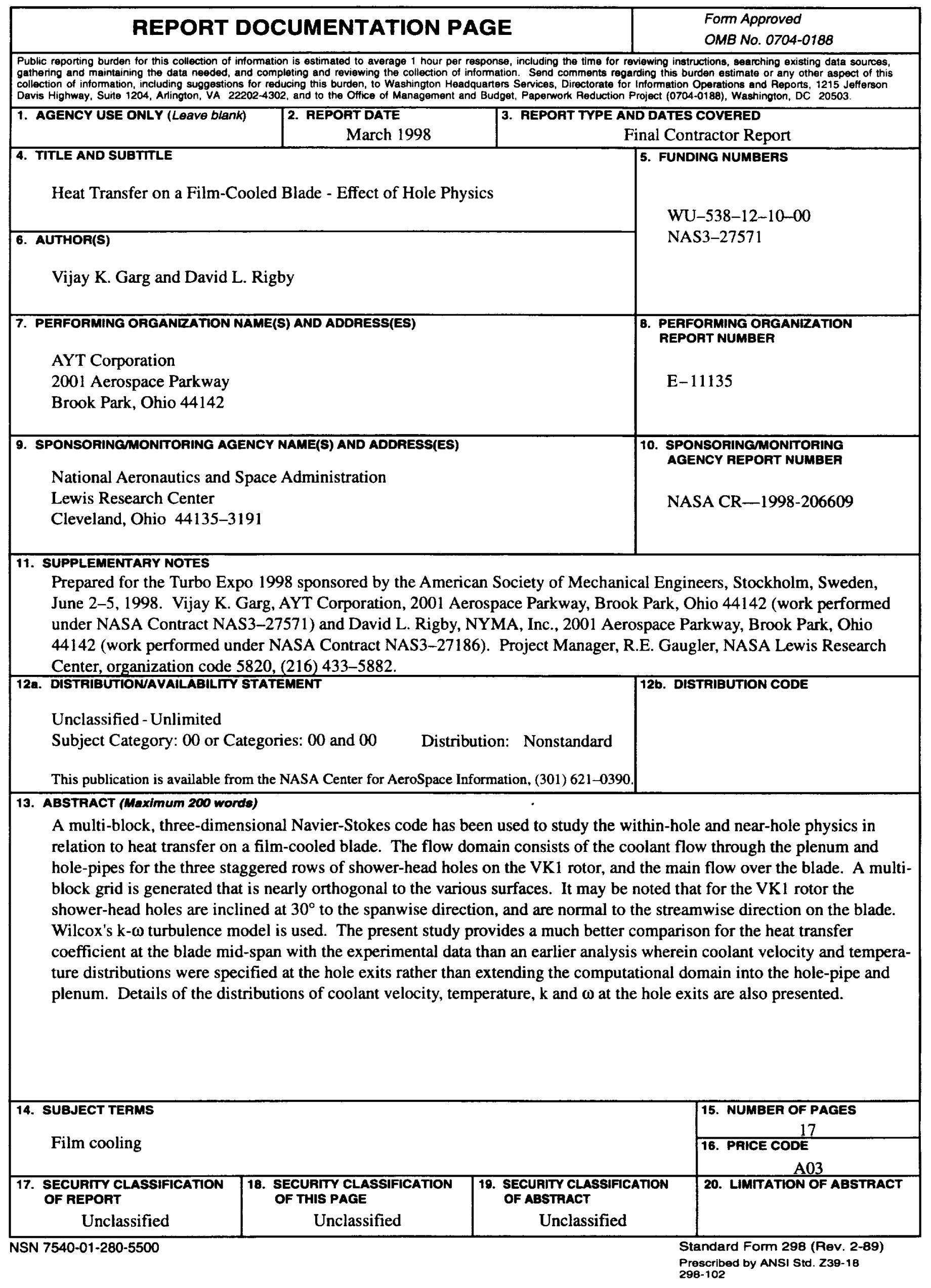

